\title{
Allelopathic effect of Eucalyptus camaldulensis and Citrus aurantium aqueous extract on germination and growth of Triticum asetivum L. (Var. Gomal)
}

\author{
Shah Khalid ${ }^{1}$, Saleena Khan ${ }^{1}$, Shariqa Zaman ${ }^{1}$, Maimoona Malik ${ }^{1}$, Hoor \\ Shumail $^{2}$, Mahnoor Hakeem ${ }^{1}$, Faiza Khisro ${ }^{1}$, Qudsia Kanwal ${ }^{1}$, Bad-e- \\ $\mathrm{Saba}^{1}$ and Syed Inzimam U1 Haq ${ }^{1 *}$ \\ 1. Department of Botany, Islamia College Peshawar, KPK, Pakistan \\ 2. Department of Microbiology, Women University Mardan, KPK, Pakistan \\ *Corresponding author's email: syedinzimam74@gmail.com \\ Citation \\ Shah Khalid, Saleena Khan, Shariqa Zaman, Maimoona Malik, Hoor Shumail, Mahnoor Hakeem, Faiza Khisro, \\ Qudsia Kanwal, Bad-e-Saba and Syed Inzimam U1 Haq. Allelopathic effect of Eucalyptus camaldulensis and Citrus \\ aurantium aqueous extract on germination and growth of Triticum asetivum L. (Var. Gomal). Pure and Applied \\ Biology. Vol. 11, Issue 1, pp35-43. http://dx.doi.org/10.19045/bspab.2022.110004
}

\begin{tabular}{llll}
\hline \hline Received: 29/01/2021 & Revised: 26/03/2021 & Accepted: 05/04/2021 & Online First: 17/04/2021 \\
\hline \hline
\end{tabular}

\section{Abstract}

The allelopathic potential of Eucalyptus camaldulensis and Citrus aurantium were investigated against Triticum aestivum L. (Var. Gomal) in the laboratory. Fresh and dry leaves (5, 10 and 15g) of E. camaldulensis and C. aurantium were soaked in $100 \mathrm{ml}$ of distilled water for $24 \mathrm{hrs}$ and $48 \mathrm{hrs}$ and were then filtered. The extract was then applied on Triticum aestivum to investigate the allelopathic impact on germination percentage, radicle and plumule length after $72 \mathrm{hrs}$ of incubation period at $26^{\circ} \mathrm{C}$. The results showed that the fresh and dry leaves extract of E. camaldulensis and C. aurantium significantly reduced the plumule and radicle length and showed a lesser effect on the germination percentage of Triticum aestivum as compared to the control. The germination percentage was effected more by $48 \mathrm{hrs}$ soaking duration extract of $E$. camaldulensis than $C$. aurantium and was recorded $24.26 \%$. The radicle length was effected more by $48 \mathrm{hrs}$ soaking duration extract of $C$. aurantium as compared to E. camaldulensis and was recorded $77.23 \%$. The plumule length was effected more by $24 \mathrm{hrs}$ soaking duration extract of $E$. camaldulensis as compared to $C$. aurantium and was recorded $91.68 \%$. From the results, it was concluded that the dry and fresh leaves extract of $C$. aurantium and $E$. camaldulensis significantly effected the growth and germination percentage of Triticum aestivum which suggests that some allelochemicals might be present in C. aurantium and E. camaldulensis.

Keywords: Allelopathy; Citrus aurantium; Eucalyptus camaldulensis; Germination percentage; Inhibitory effect; Plumule length; Radicle length; Triticum aestivum

\section{Introduction \\ Eucalyptus camaldulensis is a perennial,} single-stemmed, large-bowled, medium- sized to tall tree up to $30 \mathrm{~m}$ in height. It is commonly known as river red gum and belongs to family Myrtaceae. In Pakistan, it 
is known as sufaida or lachi. Eucalyptus camaldulensis is the most widespread member of its genus in Australia, where it is primarily a riparian species. It is evergreen perennial plant having smooth white or cream-coloured bark, lance-shaped or curved adult leaves, flower buds in groups of seven or nine, white flowers and hemispherical fruit with the valves extending beyond the rim. It is a source of timber and produces high amount of nectar due to which it is cultivated for honey purpose [1]. The genus Citrus, belonging to family Rutaceae, includes about 140 genera and 1300 species. Citrus sinensis (Orange), Citrus reticulata (tangerine) and Citrus aurantium (sour orange), are some important fruits of the genus Citrus. Citrus aurantium is a small evergreen tree in the flowering plant. Citrus aurantium is local in southeast Asia and is spread in many parts of world by humans. Bitter orange is used for their essential oil, used in flavoring, as a solvent and also found in perfumes. In marmalade production Seville variety of orange is used. It is also used in herbal medicines as a stimulant and appetite suppressant, due to its dynamic ingredient, synephrine [2, 3]. Triticum aestivum L., belong to family Poaceae. It is a cereal grain and is cultivated worldwide. After maize and rice, it is the most produced crop in the world (691 million tons per year). Triticum aestivum is the most important food crop and is grown on more area than any other crop in the world. Wheat world trade is more than any other crop plant [4]. Wheat is considered to be the first plant which is domesticated by human. The archeological and palaeobotanical records have shown that wheat has been originated somewhere in turkey [5]. The term "Allelopathy" is derived from two Greek words "Allelon" means each other or mutual and "Pathos" means to suffer i.e., the injurious effect of one upon the other. However, it refers to all biochemical interactions either stimulatory or inhibitory among plants including micro-organisms. Allelopathy generally refers to the effects of one species on the germination, growth and development of plants of another species.it is different from competition which involves the removal or reduction of some growth factors from the environment that is required by some other plants sharing the same habitat e.g., water, minerals and sunlight [6]. The phenomena of allelopathy are caused by chemical substances known as allelochemicals. Allelochemicals are secondary metabolites and are produced as byproducts of primary metabolic pathways. These chemical substances belong to different secondary compound groups, such as terpenoids, steroids, alkaloids, tannins, phenols, coumarins, flavonoids, glycosides, cyanogenics, derived from benzoic acid, fatty acids and quinones, among others. These can occur in different plant parts including, leaves, flowers, roots, rhizomes, stems and seeds. Allelochemicals can have beneficial (positive allelopathy) or detrimental (negative allelopathy) effects on the target organisms [7]. Mohsen [8] carried out an experiment on broccoli (Brassica oleracea L. var. Italica) and the main objective was to evaluate the effect of two aqueous extract concentrations of fresh leaves from Basil (Ocimum basilicum) and Eucalyptus (Eucalyptus camaldulensis) on growth of the broccoli seedlings. The growth parameters of broccoli seedling significantly were increased by basil and eucalyptus leaf extracts. The fresh and dry weight of seedling root, stem length and leaf area of broccoli seedling were also significantly increased. Also, Broccoli seedlings photosynthetic pigments chlorophyll a, b and carotenoid contents were increased. In addition, the soluble protein and the sugars metabolism were markedly enhanced. The important nutrients absorption was increased by eucalyptus extract which was reflected on the plant growth. According to Akram [9], the 
leaves, roots, bark, fruits and seeds of many plants produce allelochemicals which effect the growth and germination of another adjacent plant. They observed that aqueous extracts of Eucalyptus leaves at a concentration $10,15,20$ and $25 \%$ had negative effect on wheat germination percentage and found significantly higher fresh and dry weight of Seedling in control treatment. The inhibitory effect of the eucalyptus increased with increase of the extract concentration. This observation showed that wheat sown in field under or near eucalyptus trees has inhibitory effect on germination, growth and ultimately resulting in lower yields of wheat. Khan [10], conducted experiment to evaluate allelopathic effect of eucalyptus on the germination and seedling growth of cotton, sunflower, sorghum, mungbean and mothbean under the laboratory conditions. The results revealed that the germination and growth of roots and shoots of seedlings of crops belonging to different families was reduced and suppressed with the application of aqueous extract of fresh leaves. The orange peel after juice extraction is rich in essential oil. Essential oil of several species can inhibit the germination and growth of other species [11]. The orange peel essential oil is highly bioactive possess strong inhibitory effects on the germination and initial growth of several species [12, 13]. Moreover, Katonoguchi [14] reported that the aqueous methanol extracts of Citrus junos peel, inhibited the growth of the roots and shoots of alfalfa (Medicago sativa L.), cress (Lepidium sativum L.), crabgrass (Digitaria sanguinalis L.), lettuce (Lactuca sativa L.), timothy (Pheleum pratense L.), and ryegrass (Lolium multiflorum Lam.).

\section{Materials and Methods}

The present study investigated to compare the allelopathic potential of Eucalyptus camaldulensis and Citrus aurantium on Triticum aestivum var. Gomal. The leaves extract of these allelopathic plants were tested against germination percentage, radicle and plumule length of Triticum aestivum.

\section{Preparation of extracts}

Fresh leaves of Eucalyptus camaldulensis and Citrus aurantium were collected and are washed with distilled water. From the collected leaves some were chopped while some were kept in shade for 17 days for drying. The solution was prepared from fresh leaves in sterilized flasks using different concentrations such as $5 \mathrm{~g}, 10 \mathrm{~g}$, and $15 \mathrm{~g}$ in $100 \mathrm{ml}$ of distilled water separately and were filtered using filter paper after $24 \mathrm{hrs}$ and 48hrs. These extracts were stored in a refrigerator and are used as a stock solution. After that, dried leaves were powdered. The solution was prepared from dry leaves powder in sterilized beakers using different concentrations i.e., $5 \mathrm{~g}, 10 \mathrm{~g}$ and $15 \mathrm{~g}$ dried leaves powder in $100 \mathrm{ml}$ of distilled water and were filtered after $24 \mathrm{hrs}$ and $48 \mathrm{hrs}$.

\section{Relative toxicity of plant part}

Petri dishes were lined with doubly folded Whatman No.1 filter paper. Each Petri dish was provided with 5 healthy grains of $T$. aestivum that were placed in order on the filter paper. Before using the seeds were put in water to check the viability i.e., the seeds that settled down in water were viable seeds. The filter paper was moistened with two to three drops of leaves extract or distilled water in case of control. These Petri dishes were placed in incubator at $26^{\circ} \mathrm{C}$ for 72 hours. Each treatment and control had 3 replicates. The parameters were measured such as germination percentage, radicle and plumule length after $72 \mathrm{hrs}$ incubation.

\section{Statistical analysis}

The experiment was performed in triplicates. The data obtained was statistically analyzed using one-way ANOVA through IBM SPSS 2.0 software, followed by Dunnett's Multiple Comparison Test [15]. 


\section{Results}

Effect of 24 hours soaking duration extract on radicle length

The results showed that the inhibitory effect of Eucalyptus camaldulensis on radicle was more prominent than Citrus aurantium. From the result, it was obvious that the inhibitory effect was concentration dependent. The highest inhibition was shown by Eucalyptus camaldulensis, $15 \mathrm{~g}$ dry leaves extract which reduced the radicle length to $93.57 \%$ while lowest inhibition was shown by Citrus aurantium, $5 \mathrm{~g}$ fresh leaves extract which reduced the radicle length to $35.88 \%$ as compared to control. The results also showed that dried leaves extract was more inhibitory than fresh leaves extract (Fig. 1).

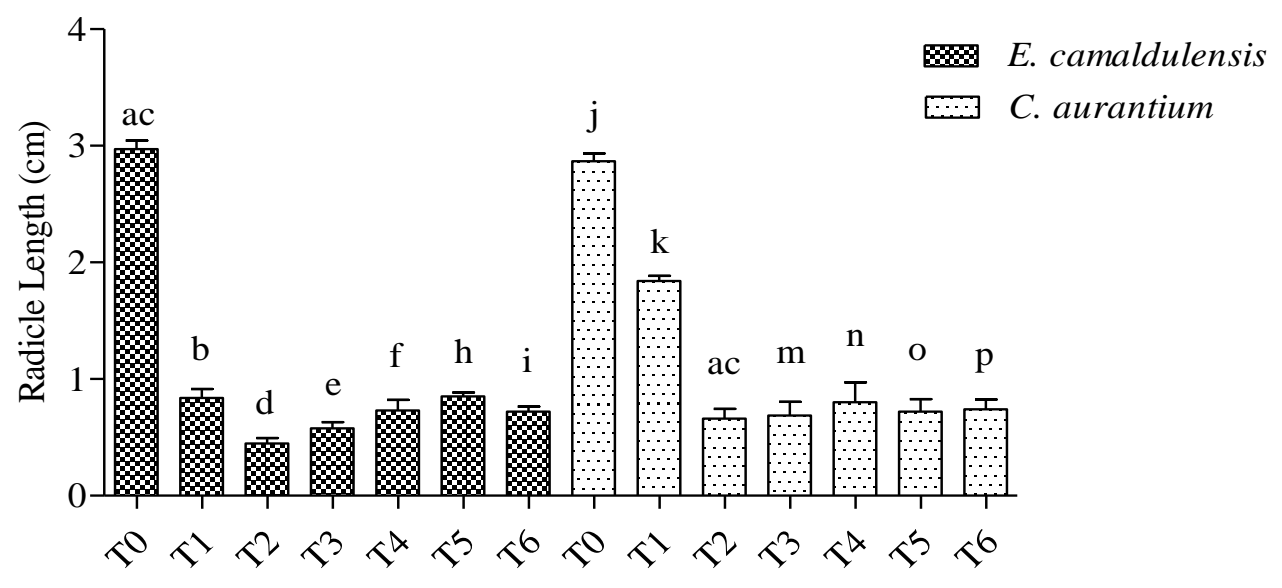

Figure 1. Effect of 24 hours soaking duration extract of Eucalyptus camaldulensis and Citrus aurantium on radicle length of Triticum aestivum. $\mathrm{T} 0=\mathrm{Control}, \mathrm{T} 1=5 \mathrm{~g}$ (fresh leaves extract), $T 2=10 \mathrm{~g}$ (fresh leaves extract), $\mathrm{T} 3=15 \mathrm{~g}$ (fresh leaves extract), $\mathrm{T} 4=5 \mathrm{~g}$ (dry leaves extract), $\mathrm{T} 5=10 \mathrm{~g}($ dry leaves extract $), \mathrm{T} 6=15 \mathrm{~g}($ dry leaves extract $)$. Bars with different letters represent significant difference at $P=0.05$

\section{Effect of 48 hours soaking duration extract on radicle length}

The inhibitory effect of $48 \mathrm{hrs}$ soaking duration extract was concentration dependent. Maximum inhibition was recorded in Citrus aurantium 15g dry leaves extract which reduced radicle length to $94.71 \%$ followed by $10 \mathrm{~g}$ dry leaves extract of Citrus aurantium which shown $93.66 \%$ inhibition while minimum inhibitory effect was observed in Citrus aurantium 5g fresh leaves extract which reduced radicle length to $41.54 \%$ as compared to the control. The results showed that Citrus aurantium showed the highest and lowest inhibitory effect as compared to Eucalyptus camaldulensis. From the results it was also observed that dried leaves extract was more inhibitory than fresh leaves extract (Fig. 2). 


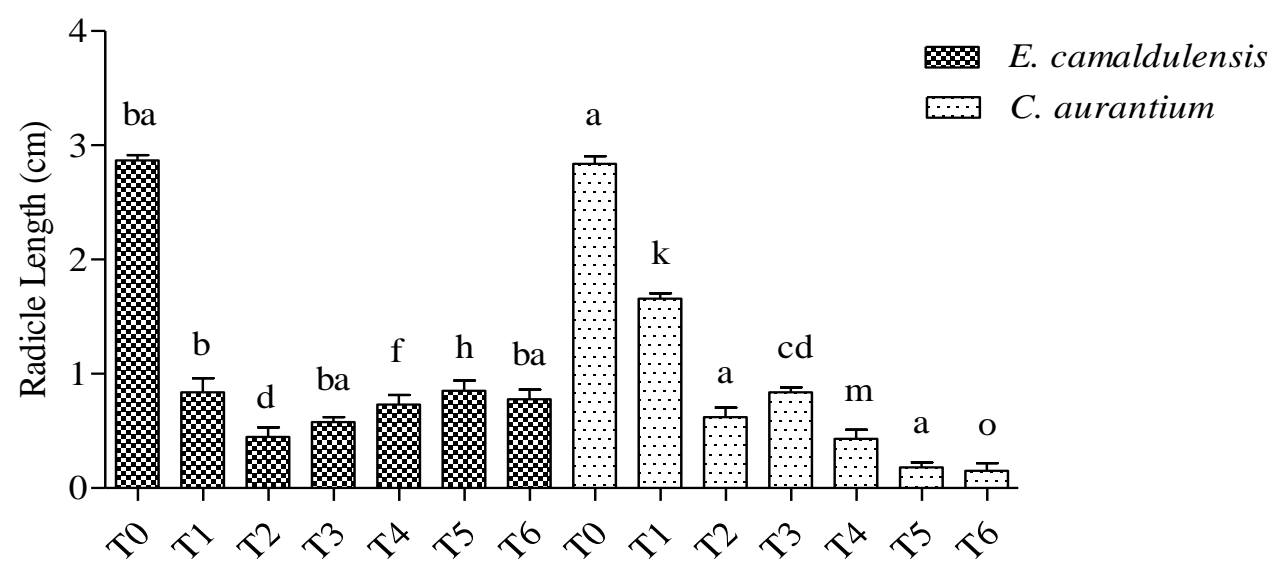

Figure 2. Effect of 48 hours soaking duration extract of Eucalyptus camaldulensis and Citrus aurantium on radicle length of Triticum aestivum. T0= Control, $\mathrm{T} 1=5 \mathrm{~g}$ (fresh leaves extract), $\mathrm{T} 2=10 \mathrm{~g}($ fresh leaves extract), $\mathrm{T} 3=15 \mathrm{~g}$ (fresh leaves extract), $\mathrm{T} 4=\mathbf{5 g}($ dry leaves extract $)$, T5 $=10 \mathrm{~g}$ (dry leaves extract), $\mathbf{T 6}=15 \mathrm{~g}$ (dry leaves extract). Bars with different letters represent significant difference at $\mathrm{P}=0.05$

Effect of 24 hours soaking duration extract on plumule length

All the treatments were inhibitory for plumule growth, but the most adverse result was shown by $10 \mathrm{~g}$ fresh leaves extract of Eucalyptus camaldulensis which reduced the plumule length to $97.70 \%$. The inhibitory effect of Citrus aurantium $5 \mathrm{~g}$ fresh leaves extract was least as compared to control which reduced plumule length to $50.38 \%$. From results, it was observed that plumule was more sensitive towards these treatments than radicle (Fig. 3).

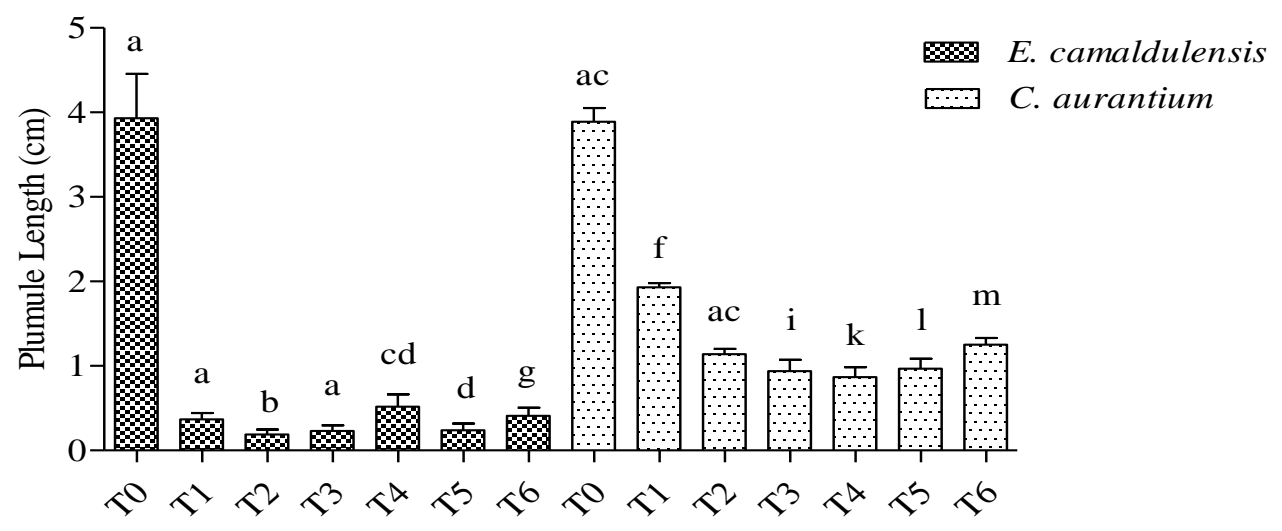

Figure 3. Effect of 24 hours soaking duration extract of Eucalyptus camaldulensis and Citrus aurantium on plumule length of Triticum aestivum. T0= Control, $\mathrm{T} 1=5 \mathrm{~g}$ (fresh leaves extract), $T 2=10 \mathrm{~g}$ (fresh leaves extract), $\mathrm{T} 3=15 \mathrm{~g}$ (fresh leaves extract), $\mathrm{T} 4=\mathbf{g}$ (dry leaves extract), $T 5=10 \mathrm{~g}$ (dry leaves extract), $\mathrm{T} 6=15 \mathrm{~g}$ (dry leaves extract). Bars with different letters represent significant difference at $P=0.05$ 
Effect of 48 hours soaking duration extract on plumule length

The (Fig. 4) showed that all the treatments were inhibitory, and this effect was concentration as well as species dependent. Higher the concentration of extract higher was the inhibitory effect. The highest inhibition was shown by $15 \mathrm{~g}$ dried leaves extract of Citrus aurantium which reduced the radicle length to $94.08 \%$ while least inhibition was shown by $5 \mathrm{~g}$ fresh leaves extract of Citrus aurantium which reduced the plumule length to $54.49 \%$ as compared to the control. It was observed from the results that plumule length was more sensitive towards Eucalyptus camaldulensis as compared to Citrus aurantium.

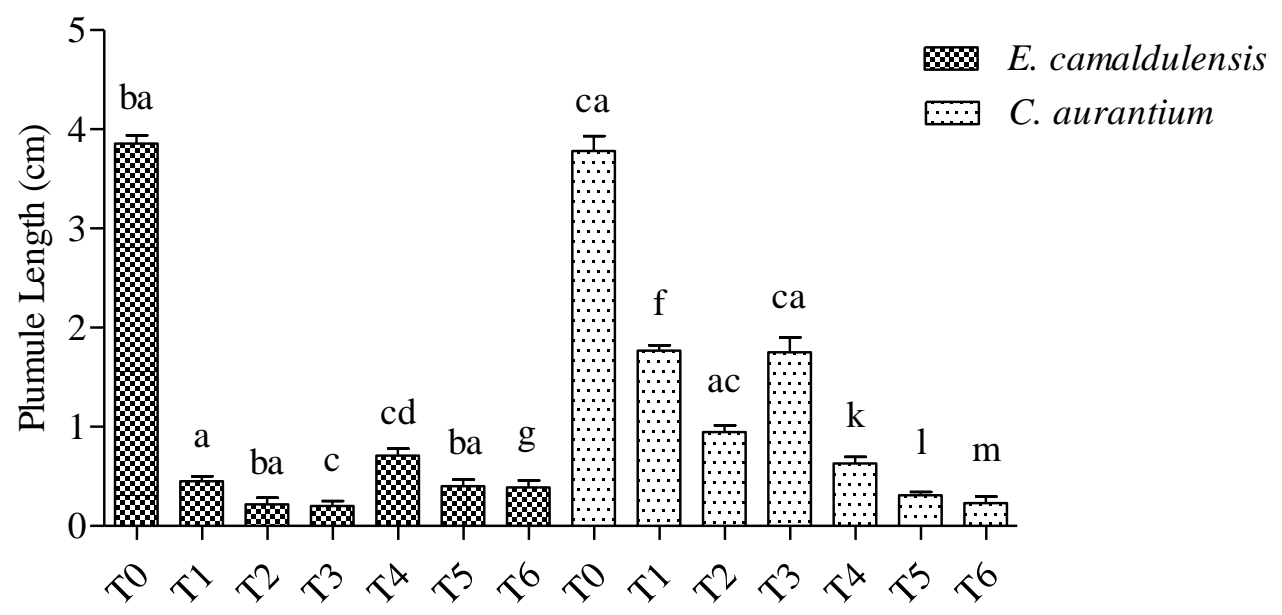

Figure 4. Effect of $\mathbf{4 8}$ hours soaking duration extract of Eucalyptus camaldulensis and Citrus aurantium on plumule length of Triticum aestivum. $\mathrm{T} 0=\mathrm{Control}, \mathrm{T} 1=\mathbf{5} \mathrm{g}$ (fresh leaves extract), $T 2=10 \mathrm{~g}$ (fresh leaves extract), $\mathrm{T} 3=15 \mathrm{~g}$ (fresh leaves extract), $\mathrm{T} 4=5 \mathrm{~g}$ (dry leaves extract), $T 5=10 \mathrm{~g}$ (dry leaves extract), $\mathrm{T} 6=15 \mathrm{~g}$ (dry leaves extract). Bars with different letters represent significant difference at $P=0.05$

\begin{abstract}
Effect of 24 hours soaking duration extract on germination percentage

As compared to radicle and plumule length, most of the treatments instead of showing inhibitory effect showed stimulatory effect on germination percentage. It was observed from the recorded data that the fresh and dry leaves extract of Citrus aurantium stimulated the germination percentage in all treatments except $5 \mathrm{~g}$ dry leaves extract. Maximum stimulatory effect was observed $44.43 \%$ in $5 \mathrm{~g}$ fresh leaves extract of Citrus aurantium whereas minimum stimulatory effect was observed $11 \%$ in $5 \mathrm{~g}$ fresh leaves extract of
\end{abstract}

Eucalyptus camaldulensis as compared to control. From the results it was also observed that the extract of Eucalyptus camaldulensis caused inhibition in all treatments except $10 \mathrm{~g}$ dry leaves extract which showed no effect and $15 \mathrm{~g}$ dry leaves extract which stimulated the germination percentage to $33.33 \%$ as compared to control. On comparing control, Maximum inhibition was recorded $55.56 \%$ in $10 \mathrm{~g}$ fresh leaves extract of Eucalyptus camaldulensis whereas minimum inhibition was recorded $11.11 \%$ in $5 \mathrm{~g}$ fresh leaves extract of Eucalyptus camaldulensis (Fig. 5). 


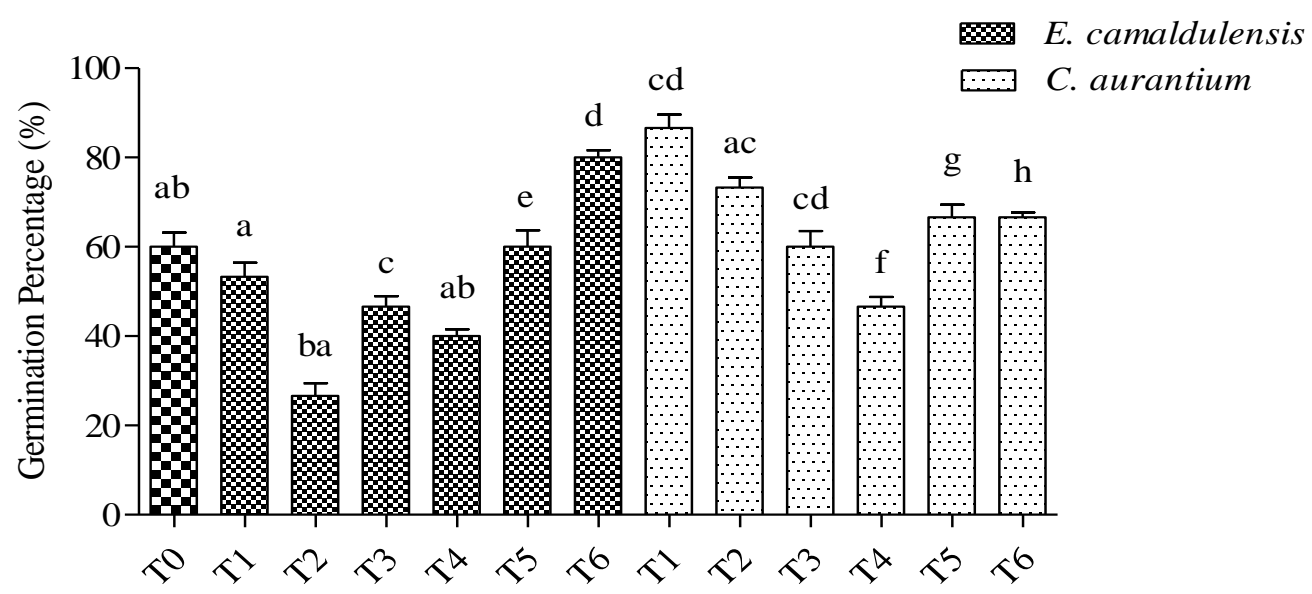

Figure 5. Effect of 24 hours soaking duration extract of Eucalyptus camaldulensis and Citrus aurantium on germination percentage of Triticum aestivum. $\mathrm{T} 0=$ Control, $\mathrm{T} 1=\mathbf{5 g}($ fresh leaves extract), $\mathrm{T} 2=10 \mathrm{~g}$ (fresh leaves extract), $\mathrm{T} 3=15 \mathrm{~g}$ (fresh leaves extract), $\mathrm{T} 4=\mathbf{5 g}(\mathrm{dry}$ leaves extract), $\mathrm{T5}=10 \mathrm{~g}$ (dry leaves extract), $\mathrm{T} 6=15 \mathrm{~g}$ (dry leaves extract). Bars with different letters represent significant difference at $P=0.05$

Effect of 48 hours soaking duration extract on germination percentage

The (Fig. 6) showed that some treatments showed stimulatory effect while some showed inhibitory effect on germination percentage of T. aestivum. Highest stimulatory effect was shown by $15 \mathrm{~g}$ fresh leaves extract of Eucalyptus camaldulensis and $5 \mathrm{~g}$ fresh leaves extract of Citrus aurantium which stimulated the germination percentage to
$33.33 \%$ as compared to control. Highest inhibition germination percentage was shown by Citrus aurantium $10 \mathrm{~g}$ dry leaves extract which reduced germination percentage to $55.56 \%$ followed by $15 \mathrm{~g}$ dried leaves extract of Citrus aurantium and $10 \mathrm{~g}, 15 \mathrm{~g}$ fresh leaves extract and $5 \mathrm{~g}$ dry leaves extract of Eucalyptus camaldulensis which reduced the germination percentage to $44.45 \%$ as compared to control.

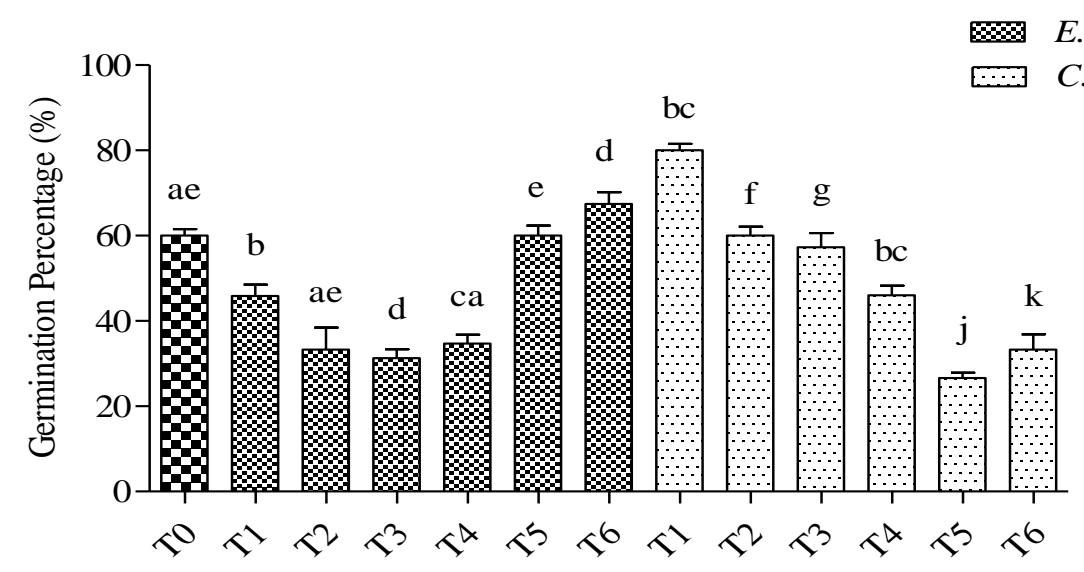

Figure 6. Effect of 48 hours soaking duration extract of Eucalyptus camaldulensis and Citrus aurantium on germination percentage of Triticum aestivum. $\mathrm{T} 0=$ Control, $\mathrm{T} 1=\mathbf{5 g}($ fresh leaves extract), $\mathrm{T} 2=10 \mathrm{~g}$ (fresh leaves extract), $\mathrm{T3}=15 \mathrm{~g}$ (fresh leaves extract), $\mathrm{T} 4=\mathbf{5 g}(\mathrm{dry}$ leaves extract), $\mathrm{T5}=10 \mathrm{~g}$ (dry leaves extract), $\mathrm{T} 6=15 \mathrm{~g}$ (dry leaves extract). Bars with different letters represent significant difference at $\mathbf{P}=\mathbf{0 . 0 5}$ 


\section{Discussion}

The results showed that the aqueous extract of Eucalyptus camaldulensis and Citrus aurantium contain phytotoxic chemicals that significantly inhibited the radicle length and plumule length whereas lesser effect was observed on germination percentage of Triticum aestivum. Highest inhibitory effect was shown by Eucalyptus camaldulensis while least inhibition was shown by Citrus aurantium. Dried leaves were more inhibitory than fresh leaves. The allelopathic effect was also dependent on concentration as well as on soaking duration. $15 \mathrm{~g}$ leaves extract showed highest inhibition followed by $10 \mathrm{~g}$ leaves extract while least inhibition was shown by $5 \mathrm{~g}$ leaves extract. Similarly, $48 \mathrm{hrs}$ extract was more inhibitory then $24 \mathrm{hrs}$ extract. The results also revealed that radicle was more sensitive towards all treatments as compared to plumule length. The results obtained showed similarity with the results of Muhammad [16]; Padhy [17]; Hoque [18]; Ahmed [19]; El-Bakkosh [20]; KatoNoguchi [21]; Kato-Noguchi [22]; KatoNoguchi [23] and Ruwanza [24].

\section{Conclusion and Recommendations}

From the results, it was concluded that leaves of Eucalyptus camaldulensis and Citrus aurantium contains allelochemicals which negatively affected plumule and radicle length while less effect was observed in germination percentage. It is evident from the experiment that Eucalyptus camaldulensis and Citrus aurantium have allelopathic potential inhibiting the radicle and plumule length of Triticum aestivum. Therefore, it is recommended that Triticum aestivum should not be planted near to these plants. Further studies should be done on these plants in order to find out allelochemicals in it as well as their mode of action. Before sowing Triticum aestivum, fields should be cleaned from the leaves of these allelopathic plants.

\section{Authors' contributions}

Conceived and designed the experiments: $S$ Khalid, Performed the experiments: S Khan, S Zaman, B-e-Saba \& M Malik, Analyzed the data: Q Kanwal \& H Shumail, Contributed materials/ analysis/ tools: M Hakeem \& F Khisro, Wrote the paper: SIU Haq.

\section{References}

1. Malik MS (2004). Effects of aqueous leaf extracts of Eucalyptus globulus on germination and seedling growth of potato, maize and bean. Allelopathy J 14: 213-219.

2. Katonoguchi H (2004). Allelopathic potential of Citrus junos fruit waste from food processing industry. Bioresource Techn 94: 211-214.

3. Moraes TM, Kushima H \& Moleiro FC (2009). Effects of limonene and essential oil from Citrus aurantium on gastric mucosa: role of prostaglandins and gastric mucus secretion. Chemico-Biol Interactions 180(3): 499-505.

4. Cutris BC (2002). Wheat in the world: Bread wheat improvement and production. Food and agric. Organization UN, Rome pp. 1-17.

5. Lev-Yadun S, Gopher A \& Abbo S (2000). The Cradle of Agric Sci 288: 1602-1603.

6. Molisch H (1937). Der Einfluess einer planzen aufdie andere Allelopathic. Gustavo Fischer J 13-20.

7. Farooq M, Jabran K, Cheema ZA, Wahid A \& Siddique KHM (2011). The role of allelopathy in agricultural pest management. Pest Manag Sci 67: 493506.

8. Mohsen AA, Elhaak, MA, Abdallah MA \& El Tanbashawy HA (2018). Response of Broccoli Seedling to Some Plant Extracts. Egypt J Bot 58(2): 195-204.

9. Akram S, Safer M, Saqlain M \& Iqbal R (2017). Effect of aqueous extract of eucalyptus (Eucalyptus camaldulensis L.) on germination and seedling of wheat 
(Triticum aestivum L.). Inter J Biosci 11(5): 286-293.

10. Khan MA, Taj I, Ahmad I \& Baloch MS (1999). Allelopathic Influence of Eucalyptus (Eucalyptus camaldulensis L.) on Germination and Seedling Growth of Crops. Pak J of Biol Sci 2: 737-738.

11. Duke SO, Dayan FE, Rimando AM, Schralder KK, Aliotta G, Oliva A \& Romagni JG (2002). Chemicals from nature for weed management. Weed Sci 50: $138-151$.

12. Sharma N \& Tripathi A (2006). Fungitoxicity of the essential oil of Citrus sinensis on postharvest pathogens. World $J$ Microbiol Biotech 22: 587-593.

13. Ali Ö \& Çelik AT (2007). Cytotoxic effects of peel extracts from Citrus limon and Citrus sinensis. Caryologia 60: 4851.

14. Katonoguchi H (2004). Allelopathic potential of Citrus junos fruit waste from food processing industry. Bioresource Techn 94: 211-214.

15. Dunnett CW (1964). New Tables for Multiple Comparisons with a Control. Biometrics 20(3): 482-491.

16. Muhammad AK, Iqtidar $H$ \& Ejaz AK (2008). Allelopathic effects of Eucalyptus camaldulensis on germination and seedlings growth of wheat (Triticum aestivum). Pak J of Weed Sci 14(1-2): 9-18.

17. Padhy BB, Patanaik PK \& Tripathy AK (2000). Allelopathic potential of Eucalyptus leaf litter leachates on germination and seedlings growth of finger millet. Allelopathy J 7: 69-78.

18. Hoque ATM, Ahmed R, Uddin MB \& Hossain MK (2003). Allelopathic effect of different concentration of water extract of Acacia auriculiformis leaf on some initial growth parameters of five common agricultural crops. Pak J of Agron 2(2): 92-100.

19. Ahmed R, Uddin MB, Khan MAS, Mukul SA \& Hossain MK (2007): Allelopathic effect of Lantana camara on germination and growth behavior of some agricultural crops in Bangladesh. $J$ For Res 18(4): 301-304.

20. El-Bakkosh AM, EI-Komy HM \& Hamed TM (2017). Assessment of allelopathic effects of eucalyptus (Eucalyptus Camaldulensis L.) plant parts on seed germination and seedling growth of wheat (Triticum aestivum L.). J of Environ Sci and Engi 1(1): 10-16.

21. Kato-Noguchia H, Tanakaa Y, Murakamib T, Yamamurac $\mathrm{S} \&$ Fujiharad S (2002). Isolation and identification of an allelopathic substance from peel of Citrus junos. Phytochem 61: 849-853.

22. Kato-Noguchi H \& Tanaka Y (2003). Allelopathic potential of citrus fruit peel and abscisic acid-glucose ester. Plant Growth Regul 40: 117-120.

23. Kato-Noguchi H \& Tanaka Y (2004). Allelopathic potential of Citrus junos fruit waste from food processing industry. Bioresour Technol 94: 211214.

24. Ruwanza S, Gaertner M, Esler KJ \& Richardson DM (2014). Allelopathic effects of invasive Eucalyptus camaldulensis on germination and early growth of four native species in the Western Cape, South Africa. South For $1-15$. 